\title{
Can Non-Invasive Methods Be Clinically Useful for Diagnosis and Severity of Portal Hypertension?
}

\author{
Ana Petrisor ${ }^{1}$, Razvan Peagu ${ }^{1}$, Dumitru Cristinel Badiu ${ }^{2}$, Ana Maria Alexandra Stanescu ${ }^{3}$, Alexandru \\ Constantin Moldoveanu ${ }^{1}$ and Carmen Fierbinteanu -Braticevici ${ }^{1,}{ }^{*}$ \\ ${ }^{1}$ Gastroenterology Department, Bucharest Emergency University Hospital, Carol Davila University of Medicine and Pharmacy, Bucharest, Romania \\ ${ }^{2}$ Department of General Surgery Clinical Emergency Hospital Bagdasar Arseni, Carol Davila University of Medicine and Pharmacy, Bucharest, Romania \\ ${ }^{3}$ Family Medicine Department, Carol Davila University of Medicine and Pharmacy, Bucharest, Romania \\ "Corresponding author: Gastroenterology Department, Bucharest Emergency University Hospital, Carol Davila University of Medicine and Pharmacy, Splaiul Independentei \\ Nr.169, 050098, Bucharest, Romania. Tel: +40-216912582, Email: cfierbinteanu@yahoo.com
}

Received 2019 December 07; Revised 2020 April 04; Accepted 2020 April 26.

\begin{abstract}
Context: Current gold standard methods of diagnosing portal hypertension (endoscopy and hepatic vein pressure gradient) are not only invasive but also very expensive. Consequently, new non-invasive methods have been studied over the years to assess their Applicability in replacing current invasive procedures. This review explores the current use of abdominal ultrasonography, Doppler ultrasonography, contrast-enhanced ultrasonography, various elastography techniques, computed tomography, and magnetic resonance imaging in evaluating portal hypertension while exploring their advantages and disadvantages.

Evidence Acquisition: We gathered data from international papers published in Pubmed/Medline, Cochrane Library, Google Scholar, Web of Science, Wiley Online Library, and Research Gate databases until October 2019. Papers analyzing the associations between non-invasive tests and either portal hypertension or its complications were included in the study.

Results: Liver stiffness (LS) and spleen stiffness (SS), regardless of the used elastography method, have shown promising results, with liver stiffness already included in current guidelines to avoid screening endoscopy. Overall, the results suggest that SS is superior to LS for screening for portal hypertension and the presence of EV, but there is a need for additional studies to certify the data and further evaluate which would provide the most accurate assessment and if other parameters need to be included to better diagnose portal hypertension.

Conclusions: Liver stiffness and spleen stiffness are the best currently available methods of detecting portal hypertension but require further research. They may reduce the number of hepatic vein pressure gradient measurements and endoscopies needed for the diagnosis and follow-up of patients with portal hypertension in the future.
\end{abstract}

Keywords: Cirrhosis, Liver Stiffness, Portal Hypertension, Spleen Stiffness

\section{Context}

Liver cirrhosis is an end-stage liver condition determined by the progressive replacement of normal hepatic structures by non-functional fibrotic tissue (1). The main complications among cirrhotic these patients are ascites, variceal bleeding, hepatic encephalopathy, hepatorenal syndrome, and hepatocellular carcinoma. A common finding in most end-stage chronic liver conditions, portal hypertension is defined as a pathological elevation of portal venous pressure due to increased intrahepatic vascular resistance and portal venous system congestion $(2,3)$. Liver biopsy, Hepatic (3). Liver biopsy, Hepatic Venous Pressure Gradient (HVPG) measurement, and endoscopy are the main diagnostic methods for detecting cirrhosis, as well as portal hypertension and its complications. How- ever, all of these methods are invasive and hold various risks and limitations.

Liver biopsy only evaluates a small sample of tissue (about 1/50,000 of the liver), which can lead to many errors.

It has high costs, has inter-observer variability, and presents some risks for the patient (4). The hepatic venous pressure gradient is currently the most studied method for the indirect grading of portal hypertension (5). The specified values are around $5 \mathrm{mmHg}$ for normal portal pressure, 6 - $9 \mathrm{mmHg}$ for subclinical portal hypertension, over $10 \mathrm{mmHg}$ for Clinically Significant Portal Hypertension (CSPH), and over $12 \mathrm{mmHg}$ for severe portal hypertension $(6,7)$. It also can be used to predict the development of varices and clinical decompensation, the out- 
come after liver resection, and hepatocellular carcinoma (8). However, since all of these methods are invasive and pose significant inter-observer variability, we need noninvasive methods that would be effective in anticipating the progression of portal hypertension and the occurrence of Esophageal Varices (EV) and their sizes (7).

In this review, we aimed to explore the use of abdominal ultrasonography, Doppler ultrasonography, contrastenhanced ultrasonography, various elastography techniques, computed tomography, and magnetic resonance imaging in evaluating portal hypertension and determine their accuracy and effectiveness in clinical settings as alternatives to current invasive methods.

\section{Evidence Acquisition}

We gathered data from international guidelines, clinical studies, articles, and reviews published in Pubmed/Medline, Cochrane Library, Google Scholar, Web of Science, Wiley Online Library, and Research Gate databases until October 2019.

Keywords used to search included "portal hypertension”, "esophageal varices”, "ultrasound”, "magnetic resonance”, "elastography”, "spleen stiffness", “computed tomography", and "non-invasive".

We selected as references only papers that analysed the correlation between non-invasive tests and the diagnosis and severity of portal hipertension.

\section{Results}

\subsection{Abdominal Ultrasonography}

There are various techniques for evaluating portal hypertension using Abdominal Ultrasonography (US), the most popular of which include B-mode US, Doppler US, and the contrast-enhanced US, each with its advantages and disadvantages.

\subsection{B-mode Ultrasonography}

B-mode US is the standard US imaging technique used for the diagnosis of cirrhosis and early detection of hepatocellular carcinoma. Pathognomonic US signs of portal hypertension are the presence of portosystemic collaterals and hepatofugal flow in the portal vein system (9). These ultrasound parameters can correlate with the aggravation of portal hypertension $(10,11)$. The benefits of any US method are accessibility, low cost, ease of transport, noninvasiveness, and rapid results. It is a safe procedure, as it uses non-ionizing radiation, and can be repeated as often as needed during follow-ups (12). The predictive value of B-mode US is low for the assessment of portal hypertension severity, as it is an indirect method that mainly determines the presence of cirrhosis, ascites, collaterals, spleen size, and portal/splenic vein diameters $(10,13)$.

\subsection{Doppler Ultrasonography}

Doppler US is a safe method used to assess the hemodynamic changes in hepatic vessels and portal vein induced by cirrhosis (14). It has similar advantages to B-mode US and can be performed as part of the same investigation. One sign of Doppler US for portal hypertension is the low portal vein blood flow velocity (time-averaged mean velocity under $14-16 \mathrm{~cm} / \mathrm{s}$ ). The sensitivity and specificity for detecting portal hypertension given in the literature are 80$88 \%$ and $80 \%$ - $96 \%$, respectively $(15,16)$.

Higher risk for decompensation is associated with lower velocity in the portal trunk $(<12.8 \mathrm{~cm} / \mathrm{s})$ in compensated cirrhosis (17). Reversed portal flow and hepatofugal venous signal in the ligamentum teres have a high positive predictive value and a high specificity for detecting portal hypertension (18). Reverse portal flow was also associated with poor prognosis in decompensated cirrhosis (17).

The continuous hepatofugal flow is present in a few percentages of patients with cirrhosis and is associated with portosystemic shunts $(19,20)$. A damping index (minimum velocity/maximum velocity of the hepatic vein waveform) of more than 0.6 was found to more likely occur in patients with significantly Severe Portal Hypertension (SPH) with HVPG over $12 \mathrm{mmHg}$, with a sensitivity of $76 \%$ and a specificity of $82 \%$ (21).

A more widely studied parameter, the portal vein congestion index showed initial good results but with no further validation for the presence of varices, large varices, and red spots (22-24). The portal-collateral circulation, ascites, and portal vein thrombosis present on Doppler US are the diagnostic signs of CSPH, but these findings are not enough to predict the presence of EV (15).

\subsection{Contrast-enhanced Ultrasonography}

Contrast-enhanced Ultrasonography (CEUS) uses a microbubble contrast agent during ultrasonography and is currently used to diagnose and differentiate various liver diseases and determine the severity of portal hypertension (25). A decrease in the transit time of the contrast agent between the hepatic vein and the hepatic artery or portal vein on CEUS has proven to be correlated with the degree of portal hypertension in cirrhosis (26). Other parameters presented for the assessment of portal pressure include the hepatic vein arrival time that measures the transit time from the venous access to the hepatic vein, regional hepatic perfusion using SonoVue, portal vein-to-hepatic 
artery strength ratio, intrahepatic transit time, the portal vein-to-hepatic artery time-intensity curve ratio, portal vein-to-hepatic artery wash-in perfusion slope ratio, and splenic artery to splenic vein microbubble transit time, all of which show good correlations with portal pressure (27). The best cutoff values of the splenic artery to splenic vein microbubble traveling time were 13.5 seconds and 14.5 seconds for CSPH and SPH, respectively (27). Accuracy parameters for the detection of portal hypertension were a sensitivity of $71 \%$ and a specificity of $68 \%$ for portal vein pressure over $10 \mathrm{mmHg}$ and a sensitivity of $60 \%$ and a specificity of $80 \%$ for portal vein pressure over $12 \mathrm{mmHg}$ (27).

In an animal study, some new CEUS parameters were proposed, aiming to evaluate the blood flow ratio between the portal vein and the hepatic artery: the area under the time-intensity curve and the portal venous phase/hepatic arterial phase (Qp/Qa and Ip/Ia, respectively) (28). In this study, Qp/Qa and Ip/Ia were found to be good predictors of increased portal pressure in liver fibrosis for use in the follow-up of chronic liver disease progression (28). Subharmonic-aided Pressure Estimation (SHAPE) seems to be associated with HVPG $(\mathrm{r}=0.82)$, but further validation is needed (29). Ultrasound-based methods have many advantages, such as high accessibility, easy bedside use, and relative cost- efficiency; however, they cannot precisely detect the presence of portal hypertension.

\subsection{Ultrasound-based Elastography}

The determination of liver stiffness (LS) has become a detection method not only for liver fibrosis but also for portal hypertension $(30,31)$. The measurement of tissue elastography can be accomplished using Transient Elastography (TE), point Shear Wave Elastography (pSWE), and two-dimensional Shear Wave Elastography (2D-SWE). All of these methods have been developed and integrated into ultrasound equipment.

\subsection{Transient Elastography}

Transient Elastography (TE), along with routine clinical examination, was proposed to be useful in the early detection of portal hypertension in asymptomatic patients with chronic liver disease (32). Transient elastography (Fibroscan and Echosens) is already being used for the measurement of LS in patients with different chronic liver diseases (33).

Concerning the advantages of $\mathrm{TE}$, it has a short procedure time, easy to evaluate patients either at the bedside or in outpatient clinics, and easy to follow up disease progression. The downsides are difficulty in obtaining data in patients with high-riding livers, narrow intercostal spaces, and hyperinflated lungs (34).
Respecting various body build types, the $\mathrm{S}$ and XL probes have been developed to remove or, at least, reduce these issues (35).

Liver stiffness measured by TE showed a good correlation with HVPG and the presence of EV; as a result, it has been evaluated as a non-invasive tool for portal hypertension quantification (36-38). The diagnostic value of TE is fair in predicting significant portal hypertension (39), with a sensitivity of $79 \%$, a specificity of $67 \%$, a positive predictive value of $93 \%$, and a negative predictive value of $35 \%$ for a cutoff of $21.6 \mathrm{kPa}$ (40). However, previous studies demonstrated that TE did not correlate well with HVPG measurements of greater than $12 \mathrm{mmHg}$ (37). Thus, TE is not accurate enough to replace HVPG in estimating the exact value of severe portal hypertension. While it cannot estimate the degree of portal hypertension as HVPG, TE can be used to avoid screening endoscopy (41). Patients with a TE value under $20 \mathrm{kPa}$ and a platelet count over 150,000 can avoid screening endoscopy because they have a low risk of having varices that require treatment (41). These patients can be followed yearly for a rise of TE values or decrease in platelet values, thus reducing the number of unnecessary endoscopies (41).

Since current medication only aims to decrease splanchnic inflow and intrahepatic and collateral resistance without affecting fibrosis, TE would not be useful in patients who are currently on portal hypertension treatment to assess treatment benefits (36).

\subsection{Point Shear Wave Elastography}

Point Shear Wave Elastography (pSWE) using an ARFI technique, entitled virtual touch quantification, is a new method of LS measurement. It showed higher applicability than TE, particularly in obese and patients with ascites (42).

Unlike TE, pSWE takes advantage of a conventional US image to choose the positioning of the Region of Interest (ROI) and is less sensitive to the presence of ascites and obesity (43).

The pSWE values give a narrow range $(0.5-4.4 \mathrm{~m} / \mathrm{s})$ compared to TE values, thus making it difficult to define the precise cutoff values for making correct decisions on patient management. The degree of liver fibrosis can be overestimated in the presence of increased central venous pressure, cholestasis, and acute cellular infiltration. Therefore, these should be taken into consideration when interpreting elastography results. Food intake can also increase pSWE values (44). It was, however, found to be a good tool for the detection of portal hypertension and EV, with a sensitivity and specificity of up to $84 \%$ and $88 \%$, respectively (45). Concerning the presence of high-risk varices, for a cutoff value of $2.83 \mathrm{~m} / \mathrm{s}$, the association between pSWE 
and splenic diameter to platelet count ratio proved to have high specificity, sensitivity, and negative predictive value (94.3\%, 90\%, and 88.3\%, respectively) (46).

\subsection{Two-dimensional Shear Wave Elastography}

The 2D Shear Wave Elastography (2D-SWE) technique is based on receiving and analyzing shear waves produced in the tissue by the passage of focused ultrasonic beams. The images are obtained in real-time with on-spot visualization of LS values (47). A prospective study that directly compared the accuracy of 2D-SWE and TE in the detection of varices reported that 2D-SWE was superior (47). Moreover, 2D-SWE allows for the real-time viewing of the area under investigation.

It appears that 2D-SWE is a promising non-invasive tool for the evaluation of CSPH in patients with advanced cirrhosis, with good diagnostic accuracy (82\%), sensitivity (81\%), and specificity (88\%) for the detection of CSPH for a cutoff of more than $24.6 \mathrm{kPa}$ for LS, but not for highrisk EV (accuracy 68\%, sensitivity $64 \%$, and specificity 100\%) (47). Moreover, pSWE and 2D-SWE have partly overcome the drawbacks of TE and have shown higher success rates (4749).

\subsection{Spleen Stiffness}

Liver cirrhosis complicated by portal hypertension induces alterations in spleen size and morphology, as a result of congestion and hyperplasia. Therefore, spleen measurements using similar techniques to liver elastography would mirror the levels of portal hypertension, probably even more accurately than do LS measurements $(26,50)$. The technical limitations of liver elastography also apply to spleen elastography.

Spleen stiffness (SS) determined with TE was found to have a good correlation with the presence of CSPH (51). Data regarding the superiority of SS over LS seem to be mixed (52). For the detection of EV, SS has shown a high negative predictive value for a cutoff value of $18.9 \mathrm{kPa}$ (53).

In another study, SS had a sensitivity of $89 \%-91 \%$ and specificity of $60 \%-64 \%$ in determining the risk of bleeding, with a Negative Predictive Value (NPV) of 92\% - 97\%, reaching an NPV of almost 100\% when associated with LS (sensitivity $100 \%$ and specificity $55 \%$ ) $(54,55)$. Such values would offer the opportunity to choose which patients can postpone or avoid performing an esophagogastroduodenoscopy.

Both LS and SS have been used to identify patients with EV at risk of bleeding. Although LS and SS can exclude the need for screening endoscopy, the results show that they cannot identify which patients with CSPH are at risk of esophageal bleeding (56). Overall, the results suggest that SS is superior to LS for screening for portal hypertension and the presence of EV (57). However, we need additional studies to certify the data and further evaluate which would provide the most accurate assessment (LS, SS, or their combination) and which elastography technique has more benefits.

\subsection{Computed Tomography}

Computed Tomography (CT) is a radiologic investigation used to evaluate the morphology of the portal venous system and identify the complications of portal hypertension: collaterals and thrombosis (58). As its advantages, CT is widely accessible, allowing a full cross-sectional evaluation of the spleen, liver, and portal venous system. Its higher sensitivity is traded against higher costs, exposure to irradiation, and the use of contrast agents with a risk of iodine contrast-induced nephropathy.

A study that measured the cross-sectional surface area of varices could distinguish mild-to-moderate varices from severe varices with a specificity of $85 \%$ - 90\% (59). A somewhat new CT technique that can indirectly assess portal pressure is the computational fluid dynamic modeling. The method is already in use in cardiology, as it allows the non-invasive visualization of coronary arteries. However, since it takes a lot of time to perform and is quite expensive, it has found no practicality in the evaluation of portal venous flow and portal hypertension $(60,61)$.

\subsection{Magnetic Resonance Imaging}

Although it is widely available, allowing a complete evaluation of the spleen, liver, and portal venous system, Magnetic Resonance Imaging (MRI) is not frequently used due to its high costs. The MRI technique has advantages as it does not emit radiation and allows the visualization of the liver, spleen, and portal system. However, compared to $\mathrm{CT}$, it has high costs, needs more time to perform, and does not provide increased accuracy in detecting varices; thus, overall, it cannot be used to screen for portal hypertension (62).

Regarding varices detection, the performance of MRI, like CT, is good for large varices, but lower for the smaller ones $(59,63)$. It can be subjected to more movement artifacts and the direct visualization of collaterals has insufficiently high sensitivity, being surpassed by CT, with or without Gadolinium administration (62). Other criteria described to be well correlated with the presence of varices in cirrhosis are the splenic apparent diffusion coefficient and the right liver lobe to serum albumin ratio (sensitivity $80 \%$ and specificity $83.5 \%$ for any varices) (64). 


\subsection{Magnetic Resonance Elastography}

Magnetic Resonance Elastography (MRE) has been used to grade the severity of cirrhosis, with the convenience of full organ coverage and low variability for stiffness measurement (65). Compared to other elastography techniques, MRE has the advantage of assessing LS and splenic stiffness over a larger tissue area. Moreover, LS and SS measured with MRE showed good correlations with HVPG values (66-69). Despite all the promising data, it has not yet demonstrated a real benefit over the use of other elastography techniques. Additionally, the cost and duration of the examination are higher and only a small number of studies are available.

\section{Conclusions}

Non-invasive methods of diagnosing portal hypertension and its complications (esophageal varices) can be clinically useful. In particular, they can reduce the number of required invasive procedures and ideally limit the procedure only to the patients requiring therapy. They are methods of monitoring portal hypertension that are easy to perform, repeatable, and easily acceptable by the patient.

Liver stiffness and spleen stiffness, regardless of the measurement method, have shown the most promising results, but more data and price comparison studies are needed to reveal the best one for each pathology. Furthermore, additional studies are needed to certify the data and further evaluate which would be the most accurate assessment tool and if other parameters need to be included to better diagnose portal hypertension. We hope that in the future, they could reduce the number of hepatic vein pressure gradient measurements and endoscopies needed for the diagnosis and follow-up of patients with portal hypertension.

\section{Footnotes}

Authors' Contribution: Study concept and design: A.P, C.F.B, and R.P; acquisition of data: D.C.B., A.M.A.S., and A.C.M; drafting of the manuscript: A.P, R.P., and A.C.M; critical revision of the manuscript for important intellectual content: A.C.M., R.P, A.P, A.M.A.S., and D.C.B; administrative, technical, and material support: C.F.B, D.C.B, and A.C.M; study supervision: C.F.B, and D.C.B.

Conflict of Interests: None to declare.

Funding/Support: No funding or support is reported.

\section{References}

1. Martinez-Esparza M, Tristan-Manzano M, Ruiz-Alcaraz AJ, GarciaPenarrubia P. Inflammatory status in human hepatic cirrhosis. World
J Gastroenterol. 2015;21(41):11522-41. doi: 10.3748/wjg.v21.i41.11522. [PubMed: 26556984]. [PubMed Central: PMC4631958].

2. Bernardi M, Moreau R, Angeli P, Schnabl B, Arroyo V. Mechanisms of decompensation and organ failure in cirrhosis: From peripheral arterial vasodilation to systemic inflammation hypothesis. $J$ Hepatol. 2015;63(5):1272-84. doi: 10.1016/j.jhep.2015.07.004. [PubMed: 26192220].

3. Sauerbruch T, Schierwagen R, Trebicka J. Managing portal hypertension in patients with liver cirrhosis. F1000Res. 2018;7. doi: 10.12688/f1000research.13943.1. [PubMed: 29780579]. [PubMed Central: PMC5934688].

4. Bedossa P, Dargere D, Paradis V. Sampling variability of liver fibrosis in chronic hepatitis C. Hepatology. 2003;38(6):1449-57. doi: 10.1016/j.hep.2003.09.022. [PubMed:14647056].

5. Groszmann RJ, Glickman M, Blei AT, Storer E, Conn HO. Wedged and free hepatic venous pressure measured with a balloon catheter. Gastroenterology.1979;76(2):253-8. [PubMed: 759258].

6. Reiberger T, Puspok A, Schoder M, Baumann-Durchschein F, Bucsics T, Datz C, et al. Austrian consensus guidelines on the management and treatment of portal hypertension (Billroth III). Wien Klin Wochenschr. 2017;129(Suppl 3):135-58. doi: 10.1007/s00508-017-1262-3. [PubMed: 29063233]. [PubMed Central: PMC5674135].

7. Bari K, Garcia-Tsao G. Treatment of portal hypertension. World J Gastroenterol. 2012;18(11):1166-75. doi: 10.3748/wjg.v18.i11.1166. [PubMed: 22468079]. [PubMed Central: PMC3309905].

8. Ripoll C, Groszmann R, Garcia-Tsao G, Grace N, Burroughs A, Planas $\mathrm{R}$, et al. Hepatic venous pressure gradient predicts clinical decompensation in patients with compensated cirrhosis. Gastroenterology. 2007;133(2):481-8. doi: 10.1053/j.gastro.2007.05.024. [PubMed: 17681169].

9. Procopet B, Berzigotti A. Diagnosis of cirrhosis and portal hypertension: imaging, non-invasive markers of fibrosis and liver biopsy. Gastroenterol Rep (Oxf). 2017;5(2):79-89. doi: 10.1093/gastro/gox012. [PubMed: 28533906]. [PubMed Central: PMC5421457].

10. Berzigotti A, Piscaglia F; Efsumb Education Professional Standards Committee. Ultrasound in portal hypertension-part 2-and EFSUMB recommendations for the performance and reporting of ultrasound examinations in portal hypertension. Ultraschall Med. 2012;33(1):8-32. quiz 30-1. doi: 10.1055/s-0031-1299145. [PubMed: 22322479].

11. Berzigotti A, Piscaglia F. Ultrasound in portal hypertension-part 1. Ultraschall Med. 2011;32(6):548-68. quiz 569-71. doi: 10.1055/s-00311281856. [PubMed: 22161554].

12. Luntsi G, Sani M, Zira JD, Ivor NC, Garba SH. Sonographic assessment of the portal vein diameter in apparently healthy adults in a Northern Nigerian population. Afr Health Sci. 2016;16(4):11638. doi: 10.4314/ahs.v16i4.35. [PubMed: 28479910]. [PubMed Central: PMC5398464].

13. Colli A, Fraquelli M, Andreoletti M, Marino B, Zuccoli E, Conte D. Severe liver fibrosis or cirrhosis: accuracy of US for detection-analysis of 300 cases. Radiology. 2003;227(1):89-94. doi: 10.1148/radiol.2272020193. [PubMed: 12601199].

14. Riahinezhad M, Rezaei M, Saneian H, Famouri F, Farghadani M. Doppler assessment of children with liver cirrhosis and portal hypertension in comparison with a healthy control group: An analytical cross-sectional study. J Res Med Sci. 2018;23:40. doi: 10.4103/jrms.JRMS_1085_17. [PubMed: 29937902]. [PubMed Central: PMC5996579].

15. Claudon M, Dietrich CF, Choi BI, Cosgrove DO, Kudo M, Nolsoe CP, et al. Guidelines and good clinical practice recommendations for contrast enhanced ultrasound (CEUS) in the liver-update 2012: a WFUMBEFSUMB initiative in cooperation with representatives of AFSUMB, AIUM, ASUM, FLAUS and ICUS. Ultraschall Med. 2013;34(1):11-29. doi: 10.1055/s-0032-1325499. [PubMed: 23129518]. 
16. Mansoor A, Shaukat R, Chaudhary AN, Jehan G. Diagnostic accuracy of Doppler ultrasonography in predicting presence of esophageal varices in patients with hepatitis-C induced cirrhosis. J Coll Physicians Surg Pak. 2019;29(7):612-5. doi: 10.29271/jcpsp.2019.07.612. [PubMed: 31253209].

17. Kondo T, Maruyama H, Sekimoto T, Shimada T, Takahashi M, Okugawa $\mathrm{H}$, et al. Impact of portal hemodynamics on Doppler ultrasonography for predicting decompensation and long-term outcomes in patients with cirrhosis. Scand J Gastroenterol. 2016;51(2):236-44. doi: 10.3109/00365521.2015.1081275. [PubMed: 26357874].

18. Gibson PR, Gibson RN, Donlan JD, Ditchfield MR, Bhathal PS. Duplex Doppler ultrasound of the ligamentum teres and portal vein: a clinically useful adjunct in the evaluation of patients with known or suspected chronic liver disease or portal hypertension. J Gastroenterol Hepatol. 1991;6(1):61-5. doi: 10.1111/j.1440-1746.1991.tb01147.x. [PubMed: 1883980].

19. Dao T, Bouvard N. Prevalence of spontaneous hepatofugal portal flow in liver cirrhosis. Gastroenterology. 1991;101(4):1141-2. doi: 10.1016/0016-5085(91)90756-b. [PubMed: 1889710].

20. von Herbay A, Frieling T, Haussinger D. Color Doppler sonographic evaluation of spontaneous portosystemic shunts and inversion of portal venous flow in patients with cirrhosis. J Clin Ultrasound. 2000;28(7):332-9. doi: 10.1002/1097-0096(200009)28:7<332::aidjcu3>3.0.co;2-9. [PubMed: 10934332].

21. Kim MY, Baik SK, Park DH, Lim DW, Kim JW, Kim HS, et al. Damping index of Doppler hepatic vein waveform to assess the severity of portal hypertension and response to propranolol in liver cirrhosis: a prospective nonrandomized study. Liver Int. 2007;27(8):1103-10. doi: 10.1111/j.1478-3231.2007.01526.x. [PubMed: 17845539].

22. Grace ND, Groszmann RJ, Garcia-Tsao G, Burroughs AK, Pagliaro L, Makuch RW, et al. Portal hypertension and variceal bleeding: an AASLD single topic symposium. Hepatology. 1998;28(3):868-80. doi: 10.1002/hep.510280339. [PubMed: 9731585].

23. Plestina S, Pulanic R, Kralik M, Plestina S, Samarzija M. Color Doppler ultrasonography is reliable in assessing the risk of esophageal variceal bleeding in patients with liver cirrhosis. Wien Klin Wochenschr. 2005;117(19-20):711-7. doi: 10.1007/s00508-005-0424-x. [PubMed: 16416372].

24. Colli A, Fraquelli M, Pometta R, Cocciolo M, Visentin S, Conte D. Renovascular impedance and esophageal varices in patients with ChildPugh class A cirrhosis. Radiology. 2001;219(3):712-5. doi: 10.1148/radiology.219.3.r01jn24712. [PubMed:11376259].

25. Maruyama $\mathrm{H}$, Yokosuka O. Ultrasonography for noninvasive assessment of portal hypertension. Gut Liver. 2017;11(4):464-73. doi: 10.5009/gnl16078. [PubMed: 28267700]. [PubMed Central: PMC5491080].

26. Bolognesi M, Di Pascoli M, Sacerdoti D. Clinical role of non-invasive assessment of portal hypertension. World J Gastroenterol. 2017;23(1):110. doi: 10.3748/wjg.v23.11.1. [PubMed: 28104976]. [PubMed Central: PMC5221271].

27. Shimada T, Maruyama H, Kondo T, Sekimoto T, Takahashi M, Yokosuka O. Impact of splenic circulation: non-invasive microbubble-based assessment of portal hemodynamics. Eur Radiol. 2015;25(3):812-20. doi: 10.1007/s00330-014-3476-3. [PubMed: 25361826].

28. Zhai L, Qiu LY, Zu Y, Yan Y, Ren XZ, Zhao JF, et al. Contrastenhanced ultrasound for quantitative assessment of portal pressure in canine liver fibrosis. World J Gastroenterol. 2015;21(15):4509-16. doi: 10.3748/wjg.v21.i15.4509. [PubMed: 25914459]. [PubMed Central: PMC4402297].

29. Eisenbrey JR, Dave JK, Halldorsdottir VG, Merton DA, Miller C, Gonzalez JM, et al. Chronic liver disease: noninvasive subharmonic aided pressure estimation of hepatic venous pressure gradient. Radiology. 2013;268(2):581-8. doi: 10.1148/radiol.13121769. [PubMed: 23525208]. [PubMed Central: PMC3721058].

30. Garcia-Tsao G, Bosch J. Management of varices and variceal hemorrhage in cirrhosis. N Engl J Med. 2010;362(9):823-32. doi: 10.1056/NE-
JMra0901512. [PubMed: 20200386].

31. Shi KQ, Fan YC, Pan ZZ, Lin XF, Liu WY, Chen YP, et al. Transient elastography: a meta-analysis of diagnostic accuracy in evaluation of portal hypertension in chronic liver disease. Liver Int. 2013;33(1):62-71. doi: 10.1111/liv.12003. [PubMed: 22973991].

32. Augustin S, Millan L, Gonzalez A, Martell M, Gelabert A, Segarra A et al. Detection of early portal hypertension with routine data and liver stiffness in patients with asymptomatic liver disease: a prospective study. J Hepatol. 2014;60(3):561-9. doi: 10.1016/j.jhep.2013.10.027. [PubMed: 24211744].

33. Sandrin L, Fourquet B, Hasquenoph JM, Yon S, Fournier C, Mal F, et al. Transient elastography: a new noninvasive method for assessment of hepatic fibrosis. Ultrasound Med Biol. 2003;29(12):1705-13. doi: 10.1016/j.ultrasmedbio.2003.07.001. [PubMed:14698338].

34. Srinivasa Babu A, Wells ML, Teytelboym OM, Mackey JE, Miller FH, Yeh BM, et al. Elastography in chronic liver disease: Modalities, techniques, limitations, and future directions. Radiographics. 2016;36(7):1987-2006. doi: 10.1148/rg.2016160042. [PubMed: 27689833]. [PubMed Central: PMC5584553].

35. Wong GL. Update of liver fibrosis and steatosis with transient elastography (Fibroscan). Gastroenterol Rep (Oxf). 2013;1(1):19-26. doi: 10.1093/gastro/got007. [PubMed: 24759663]. [PubMed Central: PMC3941434].

36. Carrion JA, Navasa M, Bosch J, Bruguera M, Gilabert R, Forns X Transient elastography for diagnosis of advanced fibrosis and portal hypertension in patients with hepatitis $C$ recurrence after liver transplantation.LiverTranspl.2006;12(12):1791-8. doi:10.1002/lt.20857. [PubMed: 16823833].

37. Vizzutti F, Arena U, Romanelli RG, Rega L, Foschi M, Colagrande S, et al. Liver stiffness measurement predicts severe portal hypertension in patients with HCV-related cirrhosis. Hepatology. 2007;45(5):1290-7. doi: 10.1002/hep.21665. [PubMed: 17464971].

38. Bureau C, Metivier S, Peron JM, Selves J, Robic MA, Gourraud PA, et al. Transient elastography accurately predicts presence of significant portal hypertension in patients with chronic liver disease. Aliment Pharmacol Ther. 2008;27(12):1261-8. doi: 10.1111/j.13652036.2008.03701.x. [PubMed: 18397389].

39. You MW, Kim KW, Pyo J, Huh J, Kim HJ, Lee SJ, et al. A meta-analysis for the diagnostic performance of transient elastography for clinically significant portal hypertension. Ultrasound Med Biol.2017;43(1):59-68. doi: 10.1016/j.ultrasmedbio.2016.07.025. [PubMed: 27751595].

40. Kumar A, Khan NM, Anikhindi SA, Sharma P, Bansal N, Singla V, et al. Correlation of transient elastography with hepatic venous pressure gradient in patients with cirrhotic portal hypertension: A study of 326 patients from India. World J Gastroenterol. 2017;23(4):687-96. doi: 10.3748/wjg.v23.i4.687. [PubMed: 28216976]. [PubMed Central: PMC5292343].

41. de Franchis R, Baveno V. Expanding consensus in portal hypertension: Report of the Baveno VI Consensus Workshop: Stratifying risk and individualizing care for portal hypertension. J Hepatol. 2015;63(3):74352. doi: 10.1016/j.jhep.2015.05.022. [PubMed: 26047908].

42. Salzl P, Reiberger T, Ferlitsch M, Payer BA, Schwengerer B, Trauner $\mathrm{M}$, et al. Evaluation of portal hypertension and varices by acoustic radiation force impulse imaging of the liver compared to transient elastography and AST to platelet ratio index. Ultraschall Med. 2014;35(6):528-33. doi:10.1055/s-0034-1366506. [PubMed: 24871695].

43. Bruno C, Minniti S, Bucci A, Pozzi Mucelli R. ARFI: from basic principles to clinical applications in diffuse chronic disease-a review. Insights Imaging. 2016;7(5):735-46. doi:10.1007/s13244-016-0514-5. [PubMed: 27553006]. [PubMed Central: PMC5028343].

44. Park Y, Kim SU, Park SY, Kim BK, Park JY, Kim DY, et al. A novel model to predict esophageal varices in patients with compensated cirrhosis using acoustic radiation force impulse elastography. PLoS One. 2015;10(3). e0121009. doi: 10.1371/journal.pone.0121009. [PubMed: 25826654]. [PubMed Central: PMC4380431]. 
45. Attia D, Schoenemeier B, Rodt T, Negm AA, Lenzen H, Lankisch TO, et al. Evaluation of liver and spleen stiffness with acoustic radiation force impulse quantification elastography for diagnosing clinically significant portal hypertension. Ultraschall Med. 2015;36(6):603-10. doi: 10.1055/s-0041-107971. [PubMed: 26565516].

46. Goertz RS, Egger C, Neurath MF, Strobel D. Impact of food intake, ultrasound transducer, breathing maneuvers and body position on acoustic radiation force impulse (ARFI) elastometry of the liver. $\mathrm{Ul}$ traschall Med. 2012;33(4):380-5. doi: 10.1055/s-0032-1312816. [PubMed: 22723037].

47. Elkrief L, Rautou PE, Ronot M, Lambert S, Dioguardi Burgio M, Fran$\mathrm{coz}$ C, et al. Prospective comparison of spleen and liver stiffness by using shear-wave and transient elastography for detection of portal hypertension in cirrhosis. Radiology. 2015;275(2):589-98. doi: 10.1148/radiol.14141210. [PubMed: 25469784].

48. Friedrich-Rust M, Nierhoff J, Lupsor M, Sporea I, FierbinteanuBraticevici C, Strobel D, et al. Performance of Acoustic Radiation Force Impulse imaging for the staging of liver fibrosis: a pooled meta-analysis. JViral Hepat. 2012;19(2):e212-9. doi: 10.1111/j.13652893.2011.01537.x. [PubMed: 22239521].

49. Sporea I, Bota S, Jurchis A, Sirli R, Gradinaru-Tascau O, Popescu A, et al. Acoustic radiation force impulse and supersonic shear imaging versus transient elastography for liver fibrosis assessment. Ultrasound Med Biol. 2013;39(11):1933-41. doi: 10.1016/j.ultrasmedbio.2013.05.003. [PubMed: 23932281].

50. Shah SH, Hayes PC, Allan PL, Nicoll J, Finlayson ND. Measurement of spleen size and its relation to hypersplenism and portal hemodynamics in portal hypertension due to hepatic cirrhosis. Am J Gastroenterol. 1996;91(12):2580-3. [PubMed: 8946990].

51. Colecchia A, Montrone L, Scaioli E, Bacchi-Reggiani ML, Colli A, Casazza G, et al. Measurement of spleen stiffness to evaluate portal hypertension and the presence of esophageal varices in patients with HCV-related cirrhosis. Gastroenterology. 2012;143(3):646-54. doi: 10.1053/j.gastro.2012.05.035. [PubMed: 22643348].

52. Takuma Y, Nouso K, Morimoto Y, Tomokuni J, Sahara A, Takabatake $\mathrm{H}$, et al. Portal hypertension in patients with liver cirrhosis: Diagnostic accuracy of spleen stiffness. Radiology. 2016;279(2):609-19. doi: 10.1148/radiol.2015150690. [PubMed: 26588019].

53. Wong GL, Kwok R, Chan HL, Tang SP, Lee E, Lam TC, et al. Measuring spleen stiffness to predict varices in chronic hepatitis B cirrhotic patients with or without receiving non-selective beta-blockers. J Dig Dis. 2016;17(8):538-46. doi: 10.1111/1751-2980.12359. [PubMed: 27185358]

54. Buechter M, Kahraman A, Manka P, Gerken G, Jochum C, Canbay A, et al. Spleen and liver stiffness is positively correlated with the risk of esophageal variceal bleeding. Digestion. 2016;94(3):138-44. doi: 10.1159/000450704. [PubMed: 27756066].

55. Karagiannakis DS, Voulgaris T, Koureta E, Chloupi E, Papatheodoridis GV, Vlachogiannakos J. Role of spleen stiffness measurement by $2 \mathrm{D}$-shear wave elastography in ruling out the presence of highrisk varices in cirrhotic patients. Dig Dis Sci. 2019;64(9):2653-60. doi: 10.1007/s10620-019-05616-4. [PubMed: 30989464].

56. Kim BK, Han KH, Park JY, Ahn SH, Kim JK, Paik YH, et al. A liver stiffness measurement-based, noninvasive prediction model for highrisk esophageal varices in B-viral liver cirrhosis. Am J Gastroenterol. 2010;105(6):1382-90. doi: 10.1038/ajg.2009.750. [PubMed: 20087336].

57. Ma X, Wang L, Wu H, Feng Y, Han X, Bu H, et al. Spleen stiffness is superior to liver stiffness for predicting esophageal varices in chronic liver disease: A meta-analysis. PLoS One. 2016;11(11). e0165786. doi: 10.1371/journal.pone.0165786. [PubMed: 27829057]. [PubMed Central:
PMC5102398].

58. Ravaioli F, Montagnani M, Lisotti A, Festi D, Mazzella G, Azzaroli F. Noninvasive assessment of portal hypertension in advanced chronic liver disease: An update. Gastroenterol Res Pract. 2018;2018:4202091. doi: 10.1155/2018/4202091. [PubMed: 29977287]. [PubMed Central: PMC6011072].

59. Kim H, Choi D, Gwak GY, Lee JH, Park MK, Lee H, et al. Evaluation of esophageal varices on liver computed tomography: receiver operating characteristic analyses of the performance of radiologists and endoscopists. J Gastroenterol Hepatol. 2009;24(9):1534-40. doi: 10.1111/j.1440-1746.2009.05849.x. [PubMed: 19486446].

60. Qi X, Li Z, Huang J, Zhu Y, Liu H, Zhou F, et al. Virtual portal pressure gradient from anatomic CT angiography. Gut. 2015;64(6):1004-5. doi: 10.1136/gutjnl-2014-308543. [PubMed: 25398771].

61. Taylor CA, Fonte TA, Min JK. Computational fluid dynamics applied to cardiac computed tomography for noninvasive quantification of fractional flow reserve: scientific basis. J Am Coll Cardiol. 2013;61(22):2233-41. doi: 10.1016/j.jacc.2012.11.083. [PubMed: 23562923].

62. Lipp MJ, Broder A, Hudesman D, Suwandhi P, Okon SA, Horowitz $M$, et al. Detection of esophageal varices using CT and MRI. Dig Dis Sci. 2011;56(9):2696-700. doi: 10.1007/s10620-011-1660-8. [PubMed: 21380758].

63. Yu NC, Margolis D, Hsu M, Raman SS, Lu DS. Detection and grading of esophageal varices on liver CT: comparison of standard and thin-section multiplanar reconstructions in diagnostic accuracy. AJR Am J Roentgenol. 2011;197(3):643-9. doi: 10.2214/AJR.10.5458. [PubMed: 21862806].

64. Li H, Chen TW, Li ZL, Zhang XM, Li CJ, Chen XL, et al. Albumin and magnetic resonance imaging-liver volume to identify hepatitis B-related cirrhosis and esophageal varices. World J Gastroenterol. 2015;21(3):98896. doi: 10.3748/wjg.v21.i3.988. [PubMed: 25624735]. [PubMed Central: PMC4299354]

65. Bensamoun SF, Wang L, Robert L, Charleux F, Latrive JP, Ho Ba Tho MC. Measurement of liver stiffness with two imaging techniques: magnetic resonance elastography and ultrasound elastometry. J Magn Reson Imaging. 2008;28(5):1287-92. doi: 10.1002/jmri.21523. [PubMed: 18972339].

66. Nedredal GI, Yin M, McKenzie T, Lillegard J, Luebke-Wheeler J, Talwalkar J, et al. Portal hypertension correlates with splenic stiffness as measured with MR elastography. J Magn Reson Imaging. 2011;34(1):7987. doi: 10.1002/jmri.22610. [PubMed: 21608066]. [PubMed Central: PMC3121904].

67. Palaniyappan N, Cox E, Bradley C, Scott R, Austin A, O'Neill R, et al. Non-invasive assessment of portal hypertension using quantitative magnetic resonance imaging. J Hepatol. 2016;65(6):1131-9. doi: 10.1016/j.jhep.2016.07.021. [PubMed: 27475617]. [PubMed Central: PMC5123896].

68. Talwalkar JA, Yin M, Venkatesh S, Rossman PJ, Grimm RC, Manduca A, et al. Feasibility of in vivo MR elastographic splenic stiffness measurements in the assessment of portal hypertension. AJR Am J Roentgenol. 2009;193(1):122-7. doi: 10.2214/AJR.07.3504. [PubMed: 19542403]. [PubMed Central: PMC2860633].

69. Levick C, Phillips-Hughes J, Collier J, Banerjee R, Cobbold JF, Wang LM, et al. Non-invasive assessment of portal hypertension by multiparametric magnetic resonance imaging of the spleen: A proof of concept study. PLoS One. 2019;14(8). e0221066. [PubMed: 31430314]. [PubMed Central: PMC6701782] 